\title{
Colonial Essentialism in Lord Lugard's “The Dual Mandate”, a Critical Textual Analysis
}

\author{
Umar Bello \\ English Language Institute, Jubail Industrial College \\ Jubail, Kingdom of Saudi Arabia
}

\begin{abstract}
The Dual Mandate in British Tropical Africa is a book written by Sir Fredrick Lugard (the first colonial Governor General of Nigeria). It forms or constructs the theoretical justification of the colonial occupation of Africa and argues about ways for its effective political control. The book grounds the philosophy and ideology of the British Empire and justify its conquests and administrative style. The elaborate justifications contained in the text, this paper argues, are made on the backdrop of purely essentialist ontology that seeks to dehumanize the subaltern and raise the status of the colonialists in Africa. The dual mandate of the British Empire, according to Lugard, is to open up Africa to the civilized world and at the same time open the African mind to civilization. The mandate itself positions a binary (or social roles) involving a civilizer and one to be civilized. Lexical and syntactical analyses are done here to capture this paternalistic and racially superior philosophy. Lugard constructs his medium and perception of the other to a state of apparent objectivity using (assumptions of) the suzerainty of his gaze, the use of the ethnographic present tense and categorical modality. These make his views appear authoritative, objective and his mission legitimated. Using this authoritativeness, the subaltern is naturalized, infantilized, distanced, fetishisized and conveniently othered as an object to be mastered and used. The data is analyzed using critical discourse analysis to demystify and unravel the mask of objectivity and the ideological significance of the style involved in the text.
\end{abstract}

Keyword: colonialism, subaltern, imperium, essentialism, critical discourse analysis, imperialism, lexical analysis, civilization, racism, postcolonial theory.

\section{INTRODUCTION}

Cesaire (1972) once draws a succinct similarity between Hitler's fascist and racist expansionism and European colonialism in Africa. What the European colonial powers did in Africa in terms of annexations, conquests and subjugation of Africa were not any less ugly than what Hitler woke up and decided to do against his European counterparts and neighbors. The only difference is probably the fact that Hitler did it alone the military style and without the phenomenal power of discursive othering of his objects and their construction into subalterns needing 'civilizational deliverance'. Cesaire $(1972,3)$ observes that:

.... It would be worthwhile to study clinically, in detail, the steps taken by Hitler and Hitlerism and to reveal to the very distinguished, very humanistic, very Christian bourgeois of the twentieth century that without his being aware of it, he has a Hitler inside him, that Hitler inhabits him, that Hitler is his demon, that if he rails against him, he is being inconsistent and that, at bottom, what he cannot forgive Hitler for is not crime in itself, the crime against man, it is not the humiliation of man as such, it is the crime against the white man, the humiliation of the white man, and the 
fact that he applied to Europe colonialist procedures which until then had been reserved exclusively for the Arabs of Algeria, the coolies of India, and the blacks of Africa.

In constructing their objects, the colonialists do not only create tags and nomenclature that easily accord their mission a justified context, but they try as well to make the colonized people see their reality within the scope of the colonial discourse they are placed, inducing the subalterns to a state of self-abnegation or self-denial. Using Foucault's discourse theory, we can see how a colonial social formation works to constitute reality and its truth not only for the objects it appears to represent but also for the subjects who form the community on which it depends. 'Truth' is to be seen as a system of ordered procedures for the production, regulation, distribution, circulation and operation of statements (Foucault 1991). 'Truth', he further maintains, is linked in a circular relation with system of power which produces and sustains it, and to effects of power which it induces and which extends it.

In constructing realities, the colonialist attempt to construct 'truths' which make themselves be seen as rescuers and civilizers and with superior culture. This can only be achieved by equally a robust attempt to deny and overlook the humanity of the colonized as a subtle tactic of creating submission and dependency. Spivak (2010) sees this as the dialectical nature of othering. This often involves a covering of tracks. If something is to appear as simply 'the case' then its origin in historical contingency must be repressed (Davis 1986). Lugard's views are products of the intellectual ferments of his moments and that of the past explorers and travelers who have catalogued and constructed the subaltern as an object. His is an intertextual build-up of both colonial mission and nature of the colonial subject. It is in fact one of the most eminent scholars of Lugard's days, Trevor-Roper who proclaims that Africa has no history until the coming of the whites (David 2010). He maintains that"

\begin{abstract}
.....Undergraduates, seduced, as always, by the changing breath of journalistic fashion, demand that they should be taught the history of black Africa. Perhaps, in the future, there will be some African history to teach. But at present there is none, or very little: there is only the history of the Europeans in Africa. The rest is largely darkness, like the history of pre-European, pre-Columbian America. And darkness is not a subject for history."
\end{abstract}

Denial of history or coevalness should be seen within the larger colonial discourse as a strategy of justifying occupation. One clear example of the subalterns acting in tandem with the colonialist is in the Satiru Rebellion in Sokoto, Northern Nigeria. The colonial army had a clash with the locals in Satiru (a village) who were resisting colonial occupation. The 'rebels' killed some officers and many of them were arrested, summarily tried and executed in the Sultan of Sokoto's palace. Not only that, the Sultan (Muhammad Attahiru II) went ahead to place a curse on the village and up till today no one resides there in Satiru attaching some superstitious jinx to the statement of the Sultan. He was afterwards given an honorary C.M.G for his loyalty to the British colonial authority during the rebellion (Umar 2006). The action of the Sultan did not only indicate his submission to the British authority but also an adopted eurocentrism in seeing the masses he was ruling within the context of the imperium i.e. the greater Other. The heroism of the people of Satiru is made to be supplanted by rebellion, their patriotic resistance by impudent recalcitrance. Similarly, Constance Belcher Larrymore, writing in 1908 in her memoirs as a wife of a British colonial resident in Katagum Northern Nigeria, reports that the 'Sarki' or the emir, 
...explained to me that, as I had evidently been sent to them as a special mark of favour, it was quite necessary for them to know my name; "what should they call me ?" "A man's name," I remarked, "is given to him by his friends. Give me a name yourselves." After cogitating in whispers, the old man said, smiling, that they would in future know me as 'Uwamu' (Our Mother), and so I received my country name, one that has stuck to me ever since, and by which I am known to all my dark-skinned friends throughout Nigeria

The emir of Katagum here accepts their subservience to the paternalistic colonialists and sees their conquerors as doing them a 'favour' by their conquest. He has seen his image within the reflective gaze of the colonial grand-autré just as the Sultan. Ashcroft, Griffiths and Tiffin (2000) argue that in colonial discourse, the subjectivity of the colonized is continually located in the gaze of the imperial Other. Subjects are thus interpellated by the ideology of the maternal and nurturing function of the colonizing entity, concurring with descriptions such as 'mother England' and 'home'. Similarly, Taiwo (2010) sees even the educated Africans deferring to the whites and acceding to their superiority. He maintains that that the educated elite shared many of the philosophical justifications of the missionizing and civilizing activities of the Europeans. They thought that the basis of the legitimacy of both the missionizing activities of the evangelists and the imperializing activities of the administrators was to be found in their claim that they were the purveyors and embodiments of a superior civilization.

All these issues do not happen by chance. They are products of a particular ideological construction; a construction that creates roles and responsibilities and that forms a default civilization. By the action of the Sultan in suppressing his people, the obsequiousness of the emir of Katagum, and to a large extent, the admittance of the African educated elite to the superiority of the colonial mission, the process of interpellation and the acceptance of the imperium have begun to be accomplished. The historical encounter between the colonialist and the colonized is real but where the issue of construction occurs is through the sort of discourse built around the encounter. Just as Laclau and Mauffe (1985), for example, see an earthquake as an event that certainly exists but whose specificity as object may be constructed in terms of natural phenomena or expressions of the wrath of God, likewise this paper sees issues as central not transcendental to their discourse. This all depends upon the structuring of a discursive field. What is denied is not that such objects exist externally to thought, but the rather different assertion that they could constitute themselves as objects outside any discursive condition of emergence (Laclau and Mauffe 1985). The Satiru encounter between the locals and the colonial army really existed, but whether this encounter is seen as an act of rebellion or an act of rightful resistance depends on how the discourse is constructed and whose voice is really more powerful and authoritative.

The attempt in this paper as such is to try to see at least one aspect of this construction i.e. in terms of the colonizers' objectification of their vision-cum-mission and the way they perceive the colonized. The colonized is an object of gaze as an other, much in consonance to the Lacanian mirror theory, and this creates what is termed as 'colonial mentality' among the conquered natives and the refrain or aversion to 'going naïve' by the dominant colonialists.

What does it mean for instance to call someone a 'savage'? What is this tagging meant to achieve? Is dehumanization in this context an end in itself or a means to an end? What do 
surrounding contexts help to show? And how do all these relate to an over-arching ideology of colonial conquest? What does it mean for instance to say with confidence and with no modals that $\mathrm{A}$ is $\mathrm{B}$ ?

The goal of analyzing these discursive practices and structures, as argued by Doty (1996), is not only to reveal essential truths that have been obscured per se, but rather to examine how certain representations underlie the production of knowledge and identities and how these representations make various courses of action possible. In essence, when I present you as a savage rather eloquently using all linguistic elements at my disposal, for instance, then it premises a reason for a particular kind of action I take which may be civilizational or salvational or both. The action is, thus, predicated on that particular way of representation or the knowledge I form.

\section{IDEOLOGY AND DISCOURSE}

Critical discourse analysis is an aspect of discourse analysis that is interdisciplinary and attempts to provide a linguistic and discursive analysis to aspects of social theory (Fairclough 2005). It attempts to show how ideology is reflected via discourse using linguistic tools and vice versa. How does, for instance, the use of an ethnographic present tense in a persistent context involving a particular kind of agency, lead or contribute to serving a macro level ideology that involves colonial conquest and domination among others? The use of an ethnographic simple present may align the production of that kind of discourse to certain authoritative stance in dealing with the objects of the discourse and in how the discourse is consumed. Ideology is defined as a 'world view' where ideologies are seen as normalized and common-sensical patterns of belief and value (Hodge and Kress 1993). Hart (2014) sees Critical Discourse Analysis (CDA) as a particular form of discourse analysis which, in one perspective at least, seeks to disclose the ideological and persuasive properties of text and talk which might not be immediately apparent without the assistance of a systemized descriptive framework such as a grammar or typology.

One crucial aspect of discourse that makes discursive construction very important ideologically is hegemony and discourse access. Hegemony leads to discourse access or the access to be heard and your world view proliferated. The dominant group in the society has better access to discourse or channels for the dissemination of information than other groups. The subaltern, in this case, is already marginalized due to lack of access to discourse. Through special access to, and control over the means of public discourse and communication, "the dominant group may influence the structures of text and talk in such a way that, as a result, the knowledge, attitudes, norms, values and ideologies of recipients are - more or less indirectly affected in their interest" (van Dijk 1996,85).

The production of the text, The Dual Mandate, in this analysis, for example, is based on the hegemonic position attained by Lord Lugard as a colonial senior officer (the Governor General of colonial Nigeria to be specific) and, ipso facto, a voice of the imperium in British Nigeria, and this also gives him the wherewithal to be published. These dominant advantages are over and above the subaltern represented in the text who does not enjoy any of the colonial privileges of getting heard or published and that is also marginalized by the linguistic medium which is English. The subaltern, in essence, lacks what Hart $(2014,4)$ calls "symbolic capital and distributional mass". Put simply, it invariably means that the ideological viewpoints of people like Lugard are those known or on offer, and the audience's choice is narrowed to that which is available and to that which is from authoritative hegemonic sources. 
The ideological viewpoints of the imperium and the agencies and narratives constructed here have, thus, the potential to be seen in terms of being the obtainable reality or the simple common sense. The colonial discourse or narrative, as discussed in the introduction, has apparently gained traction on the minds of not only the oppressed people in Africa but the educated ones. Jahoda $(1961,115)$ quoted in Ekeh $(1975,98)$ maintains that even the western educated African 'now comes to look at Africans and African culture to some extent through the eyes of those European educators who determined the manner and content of the teaching he received'. This view is also maintained by Taiwo (2010) as mentioned in the introduction.

Discourse generally has ideological effects. Fairclough (2003) argues that texts as parts of social events have causal effects in terms of bringing about changes. They bring about changes in our beliefs, attitudes, values and so forth. First, people learn from the discourses that are available, and they may form opinions about issues through a persistent exposure to a particular form of view. The persistent representation of a subaltern, for example, as a person needing civilization i.e. his infantilization or the negation of his substance may make people believe in the fact that this is a reality and that a particular course of action is required. Mental models are thus constructed about what a subaltern means and what they need and these models reinforce meaning and meanings gradually turn into established beliefs (van Dijk 1996). Hulme (1986) rightly observes that one of the ways in which ideologies operate is by passing off partial accounts as the whole story. They often achieve this by representing their partiality as what can be taken for granted, 'common sense', 'the natural', even 'reality itself'. This in turn, he continues, often involves a covering of tracks: if something is to appear as simple 'the case' then its origin in historical contingency must be repressed. Generally speaking this repression can take two forms: the denial of history, of which the most common version is the argument to nature: or the historical alibi, in which a story of origin is told.

The power of this second form, Hulme $(1986,15)$ observes, "is that it usually offers a true story, in the restricted but powerful sense but these would never be in conflict because they would be isolated from one another in separate compartments, often called 'disciplines'. Here the most pertinent disciplines are ethnography and historical linguistics, and it is the latter that seems to have provided what will look, at least for a while, like a real beginning, the first encounter."

The case for the analysis of discourse linguistically emerges, as such, out of the fact that there are elements in language that can be used efficiently to aid in the enforcement of a point of view to a level of believability and to sync well with an ideological belief as observed by Hulme (1986) above. The aim of discourse analysis here is to be able to deconstruct and reveal those mystified constructions with the aim of creating awareness. CDA thus "seeks to disclose the ideological and persuasive properties of text and talk which might not be immediately apparent without the assistance of a systemized descriptive framework such as a grammar or typology" (Hart 2014, 3).

\section{METHOD}

The Dual Mandate in British Tropical Africa is a 643-page book written by Sir F. D. Lugard in 1922. It is regarded as "the most influential book on colonial affairs in the whole inter-war period" (Hetherington 1978, 4) and the "staple diet of reading in colonial administration for young cadet officers" (Lee 1967, 43) both quoted in Doty $(1996,69)$.

The analysis in this paper is majorly concentrated on the chapter four of the book. The chapter generally discusses the colonized, their nature, their physical attributes and the like. This is where the representation of the subaltern is most discerned. As we can see from the 
composition of the chapter below (from the book), it involves a lot of representations and classifications:

\section{CHAPTER IV. \\ THE PEOPLE OF BRITISH TROPICAL AFRICA.}

Units of Administration-Climate and physical characteristics of ': the country-History-Paucity of population-Hamites and negroes-Physical characteristics of the people-Character of the typical African-Illustration of lack of apprehension-Of fidelity and friendship-Diversity in evolution-Administrative classification-Primitive races-Settled tribes-Pastorals-The refugees-Social organisation-Advanced communities-Pagan tribes-Alien conquerors-Influence of Islam-Influence of Christianity-Summary-The Europeanised African-CharacteristicsComparison with Indian Progressives-The negro in the United States —Claims for self-government-Scope in municipal work-The true path to self-government-Opportunities now enjoyed-Fitness for responsible positions-A native cadet service-Critics of the educated native-Future of the ; educated African-The debt of Africa to him-The Syrian-Is civilisation a benefit ?-Some drawbacks and some benefits

The representations done in the chapter will be analyzed using grammatical tools like the analysis of passivisation, nominalization, the use of the ethnographic present and absence of modality in some constructions. Parts of the chapter are quoted and analyzed. This attempts to show how linguistic manipulation may abet in ideological representation. At the global level of the book, there is a lexical analysis that is made on the basis of keywords in context. For instance, using Antconc concordance software I discover that the term native(s) both as a noun and adjective occurs the most apart from the usual grammatical terms or form words. Other terms that are of high occurrence involve savages, primitives, races etcetera. This use and its impact will be analyzed in the aspect of otherization and chronological distancing of the subaltern.

The analysis is made on the backdrop of Fairclough's (2001) three dimensional analytical framework, namely: description, interpretation and explanation though analyzed simultaneously not in tripartite compartments. Colonial discourse of such nature creates ways through which objects are formed, stabilized and reproduced as, and congealed into, beliefs and knowledges. Analyzing the construction of the character of a subaltern as predictable and timeless through the use of an ethnographic present tense, for instance, contributes to a higher level colonial ideology of imperial superiority and the need for the conquest of the subaltern.

\section{DATA ANALYSIS}

This part is divided into two; analysis of the colonial voice and its narrative power and the construction of the subaltern. The former is referred to here in the analyses as 'the colonialist as perfect analyst' and the latter as 'the subaltern and how their agency is constructed'.

\section{The Colonialist As A Perfect Analyst Lugardian gaze}

The gaze according to Ashcroft, Griffiths and Tiffin (2000) corresponds to the 'gaze of the grande-autre' within which the identification, objectification and subjection of the subject are simultaneously enacted: the imperial gaze defines the identity of the subject, objectifies it 
within the identifying system of power relations and confirms its subalterneity and powerlessness. One of the most powerful strategies of imperial dominaion is that of surveillance, or observation, because it implies a viewer with an elevated vantage point, it suggests the power to process and understand that which is seen, and it objectifies and interpellates the colonized subject in a way that fixes its identity in relation to the surveyor. Lugard's gaze reflects Foucault's medical gaze by a doctor who can examine and detect the faults with a patient, a diagnoses he applies on the races in Africa that he meets. The same gaze and surveillance is used by the colonialists in reporting and describing the colonized. The power of the gaze is able to instantly produce such knowledge as contained in the chapter in terms of people's nature, culture, psychology, strength, morality etc.

This surveillance accords objectivity and ocular prowess to them and places the object as "knowable, visible objects of disciplinary power" (Doty 1996, 11). Appearances and the outward become evidences of deeper realities and Lugard is able to analyze cultures of the people by their looks and the hue of their skin. This is akin to medical diagnosis and the overall essence of the 'glance' or the 'suzerainity of the gaze" which simply exercises its rights of origin over truth (Foucault 1974).

Similarly, Lugard's gaze socially pathologizes certain races in Africa with some authority. His theory here suggests that the blacks are innately bad and whites are innately good. This argument appears to be hinged on the pathology of colour. This shall be discussed later. The Lugardian gaze and its construction has built up such important aspects of the chapter as discussed in sub-units as the following:

Paucity of population-Hamites and Negroes-Physical
characteristics of the people-Character of the typical
African-Illustration of lack of apprehension-Of fidelity
and friendship-Diversity in evolution-Administrative
classification-Primitive races-Settled tribes-
Pastorals-The refugees-Social organisation-Advanced
communities-Pagan tribes-Alien conquerors-Influence
of Islam (64)

Most of the topics discussed above require specialist and scientific evaluations, but Lugard is able to give a seemingly authoritative accounts of all those topics and many others by dint of his gaze which is accorded a lot of prowess. This issue is not without precedence especially through the activities of British explorers who are seen in history as ethnographers by their assessment using the visual. Ekeh (1975) observes that Mungo Park, an adventurer, becomes a 'discoverer' in colonial history taught in British colonized nations. The power of the gaze comes with the potency of surveillance which accords power to the former. This results in conversion and the metaphor of the panopticon indicating the overall essence of making the objects of colonial discourse be interpellated. When you are known to be surveyed as in the prisons you tend to align your behavior to be in conformity with the expectations of the surveyor. We can safely locate the behavior of the emir of Katagum as an object of surveillance, for instance, in terms of his adjustment of behavior to please his gazers or his grand autres or surveyors. Quite in consonance with the Lacanian other and the gaze of the child, the colonial subject gains their identity and image from the mirror held by colonial discourse and authority.

\section{Use of Categorical modality}

According to Machin and Meyer (2012) epistemic modality deals with speaker's/author's judgment of the truth of any proposition like in the use of 'may', 'probably', 'certainly', 
'perhaps' etc. Absence of epistemic modality expresses objectivity and surety. One thing that is striking about the views of Lugard is the sense of authority and veracity with which he reports his objects. "The gaze is disembodied here - statements are made as if there is no seer behind the observations" (Anand 2007, 16). It happens as if the objects signal their own description and prescription without any form of agent mediation. He uses constructions that do not bear any sense of subjectivity due to absence of epistemic modals. In saying that A is B without an epistemic doubt, the copular 'is' there has diminished any sense of difference. The examples below from the Dual Mandate show a surety of views regarding the African by Lugard:

He sacrifices life freely under the influence of superstition, or in the lust and excitement of battle, or for ceremonial display.

He lacks power of organisation, and is conspicuously deficient in the management and control alike of men or of business.

He loves the display of power, but fails to realise its responsibility.

His most universal natural ability lies in eloquence and oratory.

He is by no means lacking in industry, and will work hard with a less incentive than most races.

He has the courage of the fighting animal-an instinct rather than a moral virtue.

$\mathrm{He}$ is very prone to imitate anything new in dress or custom, whether it be the turban and flowing gown of the Moslem, or the straw hat and trousers of the European, however unsuited to his environment and conditions

He is an apt pupil, and a faithful and devoted friend. (P6970)

Absence of epistemic modality "supports a view of the world as transparent-as if it signals its own meaning to any observer" (Fairclough 2001, 107). Reality is reported as just given and transcendental what Simpson $(1993,49)$ argues is "expressing basic proposition in its 'raw' form".Statements disembodied like those in the examples present reality and textual representation as indistinguishable.

\section{Use of the ethnographic present tense}

The overall chapter, especially where descriptions of Africans are made, is in the ethnographic simple present. Apart from the absence of modality mentioned above, the ethnographic simple present tense lends itself to making constructions that freeze societies and contain assumptions that make objects and their attributes repetitive, predictable, timeless and conservative (Fabian 1983).

According to Downing and Locke (2006) the present tense is the unmarked tense which cognitively expresses situations which have immediate reality, i.e. what is currently observed and which semantically covers a wider range of temporal references than the past tense, including reference to future time. In the use of copular verbs or linking verbs (mainly 'be' and 
'have') the function is "to carry tense and to relate the Carrier to its Attribute, the Identified to its Identifier and the Possessor to the Possessed" (Downing and Locke 2003, 144). In the examples below, we can see the ethnographic simple present in action.

He is by no means lacking in industry, and will work hard with a less incentive than most races.

He has the courage of the fighting animal-an instinct rather than a moral virtue.

He is very prone to imitate anything new in dress or custom, whether it be the turban and flowing gown of the Moslem, or the straw hat and trousers of the European, however unsuited to his environment and conditions

He is an apt pupil, and a faithful and devoted friend. (p70)

Actions are not shown here but states. The resort not to use a material process here is germane as such a process involves detailing of actions and circumstances and thus needs facts. A relational process is handier in showing state of affairs which acquit one of the need for verifiability. The ethnographic sentence comes with other clauses as well. In addition, about three issues are immediately clear in the examples above. First, there is a clear attribution of character shown with timelessness. Secondly, there is the speaker's implicit authority and ability to make such commentary. Thirdly, there is the issue of the use of 'he', templated as a general reference to all the black Africans (more is discussed on the issue of such pronouns in fetishisizing the subaltern).

Moreover, Davis (1992) argues that the present tense can be used in about eight cases. It can be used as synopsis of a play, liturgical instructions in religious settings, for stage directions, in explaining photographs and maps and in science with facts especially when something is true by definition and true by induction and experience. It poses an ethical problem when the ethnographic present is used in explaining anthropological points about people with the timelessness of photographs or the predictability of physical science properties. Davis (1992, 206) gives an example of true by definition:

In any normal distribution, 68 per cent of the observations

fall within one standard deviation of the mean.

And true by induction and experience as in:

If a quantity of heat $Q$ is supplied to any substance at a constant temperature $t$, the work $\mathrm{dW}$ obtainable from $\mathrm{Q}$ by an ideal reversible engine working in a cycle of range $\mathrm{dt}$ must be proportional to Qdt multiplied by some function of the temperature, $\mathrm{ft}$, which must be the same for all substances. (Carnot's Principle-the Second Law of Thermodynamics)

The two examples above do not show a remarkable difference from Lugard's assessment of black Africans below:

They vary in their mental and physical characteristics according to the amount of Negro blood in their veins, 
which has shown itself extremely potent in assimilating alien strains to its own type (p67)

Lugard's statement exposes the knowability and assessability of the subaltern by the strength of the gaze and his own omniscient observation. With the aspects of scientific testability manifested in the two examples by Davies showing permanence of results, Lugard's statements are similarly couched to show permanence of result in the collective nature and behavior of the Africans. In essence, Lugard uses or deploys a scientific orders of discourse to discuss people's mental and physical characteristics but using the suzerainty of his gaze as his tool. Lidchi (1997) sees such actions in colonial discourse as a blurring of science and popular anthropology in subtle ways to legitimize European imperial superiority.

\section{The Subaltern And How Their Agency Is Constructed Naturalization of the subaltern}

In this case, the subaltern is naturalized in such a way as to show nature and culture merging into each other. This argument also attempts to relate biology with anthropology and psychology. Lugard sees the physical nature of the blacks and its shades and hues of color in direct correlation with their intellectual and organizational advancement. The mixture of the blacks with the Hamites connote 'pollution' and dilution that possibly affect their nature and culture. He says

The principal Hamite-or Hamitic Negroid-tribes in East Africa are the Abyssinians, the Somalis, the Gallas, the Masai, the Wahima, and the Nandi; in West Africa the Fulani, supposed to be descended from the Berbers. All have been modified to a greater or less degree by admixture with Negro blood, which has produced racial types differing from each other, and widely different from the Negro type. They vary in their mental and physical characteristics according to the amount of Negro blood in their veins, which has shown itself extremely potent in assimilating alien strains to its own type. (p. 67)

In fact the fusion of what Lugard calls the Hamites and the Negros produces a race type with traits that are diametrically opposed like the fusion of black and white which produces a hue that neither is its parent in its original form. He continues:

Perhaps the most distinctive external characteristic-much more reliable than that of colour-by which the degree of Negro blood may be gauged, is the hair growth on the head and face, varying from the woolly head and smooth face of the pure negro, to the straight hair and bearded face of the Asiatic.

The Hamites and Hamitic negroids are "slim and wiry in build, markedly dolichocephalous, with high narrow foreheads, good features, reddish complexions, plentiful frizzy hair, and small hands and feet." They exhibit, as we shall see, powers of social organisation and intellectual development in advance of the pure Negro stock. They are capable of immense physical endurance, but do not possess the physique and strength of the negroes.......The finer negro races, among whom are included the group of tribes 
known as the Bantus, have no doubt in prehistoric times assimilated alien blood, which has differentiated them from the aboriginal negro type...... The skull and forehead are better developed, and the thick lips, the bridgeless nose, and the prognathous jaw are less pronounced than in the more archaic type. Their intelligence is more developed, and many tribes have reached a degree of social organisation ......67-68

Here, we see how people are essentialized on the basis of their physical nature especially their hair and color. The 'pure negro' as Lugard calls them appear to be primitive and underdeveloped and the instances of organization and skills exhibited are from those cultures that intermarry and produce a race. Frederickson (1987) sees this profiling as using the physiological and anatomical differences especially in cranial features and facial angles to explain mental and physical inferiority. There is a clear subjective assessment that appears to, by dint of the colonial gaze and account to be the gospel truth. The power of ocular surveillance and the imperial gaze simply supplant an objective anthropological and ethnographic scientific inquiry. The body thus simply becomes "the totemic object" (Green1 1984, 31) that articulates nature and culture by its appearance.

Hall $(1987,284)$ argues that this discursive construction of showing nature and culture as the same is a tactic that serves colonial interests. By consigning the blacks behavior as a fixed unchanging nature then the quest to dominate is justified since they can't be taught civilized culture. He maintains that "among the whites, culture was opposed to nature. Among blacks it was assumed that culture coincided with nature." Generally, by putting forth the light hue of skin, finer bone composition and unwoolly hair as premises of argument in support of racial superiority, Lugard, by implication, is raising the European picture as highly civilized because they possess those features in great supply. The African Hamites do not possess the light hues and silky hair and are not bearded as much as the European, and since body composition and color show advancement and refinement then this discourse serves his essentialist superior perspective. This binary opposition, Doty $(1987,3)$ argues, "serves as a site for the selfelaboration of the colonialists" just as in the term 'third world' which serves as a site for the self-elaboration of the 'first world' and the representational practices that have constructed one have simultaneously constructed the other. This makes Achebe $(1977,1)$ sees the colonialists as setting up Africa "as a foil to Europe, as a place of negations at once remote and vaguely familiar, in comparison with which Europe's own state of spiritual grace will be manifest."

Similarly, Like nature, Doty $(1996,63)$ observes that "the 'native' body becomes objectified; it is an object to be conquered, controlled, and mastered. The humanity of the 'native' is denied. His being is reduced to the materiality of his body." We see this mastery in the ocular colonial vision of assessment and we see this as well in his discussion of Bantu's strength.

The Bantus, and most other Negroes, are physically fine specimens of the human race. Powerfully built, they are capable of great feats of strength and endurance. Individuals will carry a load of 100 Ibs. On their heads up hills and through swamps, with but brief intervals for rest..(p 68)

The mastery of the body here is manifest in the above quote which also tends to objectify it as a resource. The Bantus here are shown to be good due to their hard work. This earns them some recognition among the colonialists like Lugard. They are recognized by virtue of their strength 
which can be deployed to colonial advantage. Doty $(1996,62)$ sees this in parody of the Cartesian philosophy "I think, therefore I am", to, for the African subaltern, "I work, therefore I am". She argues that the privileged position of this signifier presumed that the locus of "native" being was in the physical body and the efficient uses to which it could be put. The subaltern thus gains their humanity by the physical not the intellectual.

\section{The chronological distancing of the subaltern}

This aspect is referred to as 'chronopolitics'. Wallis (1970) sees chronopolitics as a term descriptive of the relation of time perspectives to political decision-making. In colonial discourse, it is a very effective way of throwing the subaltern back in time. He is construed in terms of spatial and temporal distance. This brings about an anthropological conundrum or a contradiction. While the colonial subject is here materially as a contemporary, he is seen in terms of construction that dates him far back in time in terms of evolutionary calendar. Fabian (1983, XI) captures this aptly as the Other's empirical presence turning into his theoretical absence, "a conjuring trick which is worked with the help of array of devices that have the common intent and function to keep the Other outside the Time of anthropology." The Dual Mandate has a lot of constructions that builds the African subaltern in terms of prehistoric chronicle. In this chronopolitics, there are aspects of hierarchization of races and classification.

\begin{tabular}{|l|l|}
\hline Words & Tokens \\
\hline Tribe(s) & 234 \\
\hline Primitive & 107 \\
\hline backward & 21 \\
\hline Savage and savagery & 19 \\
\hline Archaic & 4 \\
\hline Tribal & 129 \\
\hline
\end{tabular}

Table 1

The terms in Table 1 indicate groupings, primal attitudes and nature of man at the early stage of evolution. The use of terms such as 'backward', 'primitive', 'feudal', 'medieval', 'developing country' and 'pre-industrial' to describe colonised countries, Fabian (1983) argues, the colonised country is set within a distant period of British historical development or Western progress and is therefore not permitted to exist on its own terms; it exists only in an underdeveloped parody of British civilization and empire. Fabian calls this tactics the denial of the subaltern his coevalness or contemporaneity. Quoting Sir C.Eliot, Lugard states that the African mind:

is far nearer to the animal world than that of the European or Asiatic, and exhibits something of the animal's placidity and want of desire to rise beyond the state he has reached.. (p69)

This again clearly captures the idea of the evolutionary primal nature of the black African. Time is here shown to be frozen and congealed with the black race.

\section{Negation of the substance of the subaltern}

There is here a negation of history and civilization. The denial of history could be attributable to the exigencies of colonialism. Two important formulations here by Lugard are significant in seeing how such negation of historical roots could be discerned and better evinced using linguistic resources:

The history of these peoples of tropical Africa, except on the coast fringe, has during the ages prior to the advent of 
European explorers some sixty years ago been an impenetrable mystery. Attempts to solve it consist chiefly in conjectural migrations of tribes and of mythical legends, except in so far as the history of the West African empires of Ghana, Melle, and Songhay have been recorded by the Arabic historians of the Moorish Empire.(p66)

This statement in the first sentence is totally in the passive tense and it obfuscates the 'doer' of the action or the grammatical subject. To whom has the history been a mystery? The word 'mystery' is also a term that is subject to manipulation because it is the naming of a process, a floating signifier that is. What is 'Mystery' to this discourse may not necessarily be mystery in another. Its truth as such has resonance only within its formulation at a higher level of discursive construction. The subsequent sentence talks about 'attempts' which is a nominalization. Nominalization is a very powerful option in the presentation of information. This is because "It reconceptualises an event as a participant, with the consequent restructuring of the rest of the clause, which influences the way the information is perceived....With this new status as a referent, a nominalisation can give the impression that what it expresses is a recognised piece of information, whose validity is beyond dispute" (Downing and Locke 2002, 160). In this case we see a process frozen and becoming a subject to an entirely different sentence. In a way the discourse it freezes has been taken for granted. The 'attempts' - in itself-- encompasses the subjects, the processes, the circumstances etc. into one element. Here there is no room to challenge the assertion on the basis of truth since no name or dates are clearly made. It should thus be assumed that these 'attempts' are just the case.

The overall thrust of this discursive construction here as such is to show a people with no clear history and much in consonance with the Trevor-Roper theory of Africa lacking in history. This discourse would sync well with the paternalistic posture of the colonialists. Similarly, Lugard denies the Africans the ability to evolve a religion. He says:

Through the ages the African has evolved no organised religious creed, and though some tribes appear to believe in a deity, the religious sense seldom rises above pantheistic animism, and seems more often to take the form of a vague dread of the supernatural. (p69)

Absence of religion, history and culture conjures of the image of a people incapable of selfcivilization and self-discipline which makes a case for those on a redeeming civilizational mission like Lugard. Anand $(2007,59)$ maintains that negation serves to erase what one sees in order to clear 'a space for the expansion of the colonial imagination and for the pursuit of desire. This, in colonial times, led to ground clearing for the expansion of colonial rule in places including Americas, Australia, and parts of Africa. Absence of "organized creed" makes a case for an organized creed, and presence of "pantheistic animism" makes a case for sane monotheism. The binary is thus the presence of African culture translates into absence of superior civilization.

\section{Infantilization of the subaltern}

Infantlization happens when the subaltern is represented as a baby or a child that needs parental care and guidance. Lugard observes that:

In character and temperament the typical African of this race-type is a happy, thriftless, excitable person, lacking in self-control, discipline, and foresight, naturally courageous, 
and naturally courteous and polite, full of personal vanity, with little sense of veracity, fond of music, and "loving weapons as an oriental loves jewelry." (p69)

In the above quote there is clearly a representation of 'the typical African' as happy, thriftless, excitable and lacking in discipline, self-control and so forth. All these connote childlike tendencies and a lack of maturity and responsibility. He continues:

His thoughts are concentrated on the events and feelings of the moment, and he suffers little from apprehension for the future, or grief for the past.

"His mind," says Sir C. Eliot, "is far nearer to the animal world than that of the European or Asiatic, and exhibits something of the animal's placidity and want of desire to rise beyond the state he has reached,"(p69)

...In brief, the virtues and "the defects of this race-type are those of attractive children, whose confidence when once it has been won is given ungrudgingly as to an older and wiser superior, without question and without envy.

Such in brief are the peoples for whose welfare we are responsible in British tropical Africa. They have a fascination of their own, for we are dealing with the child races of the world, and learning at first hand the habits and customs of primitive man.... (p72)

What all this construction creates is the need for a paternal image and the unstated implicature is that the colonialists have the opposite of the traits they ascribe upon the subaltern. It clearly makes a case for control. 'Thriftlessness' of the subaltern invites the 'thriftiness' of the imperium. His 'lack of self-control, discipline and foresight' makes a case for a paternal image ready to provide 'control, discipline and foresight'.

Similarly, there are other terminologies of control that tend to prove the issues of subordination and control. The word 'dependencies' appears 125 times in the overall text in reference to British colonies. In particular "our African dependencies" occurs six times. Moreover, the term 'protectorates' appears 74 times. Referring to African nations as 'dependencies' and 'protectorates' captures the image and relationship in the aspect of infantilization and its equal binary which is patriarchization. 'Dependency' shows a relationship of reliance and lack of independence and a 'protectorate' shows that of a greater entity protecting a weaker one. The colonies, thus, are dependent on the imperium which protects them like parents do to their wards.

\section{Fetishisization of the subaltern}

Hill (1997) argues that fetishism involves displacement. The Marxist notion of 'commodity fetishism' involves the displacement and disappearance of the living labour of workers into commodities. This can also happen in representation when you displace, reduce and dissimulate identities, sexuality, ethnicity and individuality into an omnibus like generic terminology. Lugard employs this strategy in his use of possessive and personal pronouns to refer to the whole Africans. 


\begin{tabular}{|l|l|}
\hline Words & Tokens \\
\hline he & 858 \\
\hline his & 1076 \\
\hline The african & 138 \\
\hline The negro & 21 \\
\hline
\end{tabular}

Table 2

In the use of 'he' and 'his' to refer to all Africans, apart from some few anecdotal cases involving clear references, all other cases are a blanket reference to a whole people. Fabian (1983) argues that that use of personal pronoun like 'he' or 'she' or 'it' presents people as outside and not spoken to but posited (or predicated) as that which contrasts with the personness of the participants in the dialogue. This removal from the dialogic situation, he argues, is another way to describe a denial of coevalness. In addition, terms like 'the African' or 'the negro' simply treat a whole people as one, fetishizing issues of differences like sexuality, ethnicity, individuality and the like. There is also an intertextual relationship there involving presupposition in the use of definite 'the' or the possessive pronoun 'his'. These constructions assume some givennness and a state of being the case already known. All the structures connote uniformity, lack of dynamics and a complete lack of individuality. People are treated en masse and en bloc which may lead to racial profiling and stereotyping

\section{Otherization of the subaltern}

This is a process of colonial discourse that alienates the colonial subject while at the same magnifying the strength of the colonizer. One can argue that all the other points discussed above constitute a kind of othering. However, there are other forms of othering that are more obvious and manifest especially with the use of prenominal modifiers. Modifiers here are used as a form of creating distinction and difference. Nearly all institutions related to the subaltern are differentiated with modifiers by the use of the adjective 'native'. Fowler and Kress (1979) maintain that a predicative modification indicates a writer's evaluation, but a prenominal modification indicates classification and a sort of orientation towards a generalized belief. Similarly, Hodge and Kress $(1993,104)$ see the process as the absorption of the attributive model into the transactive i.e. "the act of judgement expressed in the attributive model thus becomes a part of the actor/nominal in the transactive model. The premodifying adjectives also have powers of presupposition for they tend to make what is modified taken for granted. The term 'native(s) as a noun and Adjectives occurs 1705 in the data. According to Ashcroft, Griffiths and Tiffin $(2000,142)$ :

the root sense of the term as those who were 'born to the land' was, in colonialist contexts, overtaken by a pejorative usage in which the term 'native was employed to categorize those who were regarded as inferior to the colonial settlers or the colonial administrators who ruled the colonies. 'Native' quickly became associated with such pejorative concepts as savage, uncivilized or childlike in class nouns such as 'the natives'. The idea that 'the natives' were members of a less developed culture that required colonial nurture to bring it to modernity and/or civilization permeated colonial discourse. 
The term has modifiers as in the following:

\begin{tabular}{|l|l|}
\hline The Modifier 'Native' & Tokens \\
\hline Native administration & 115 \\
\hline Native courts & 143 \\
\hline Native rule(rs) & 83 \\
\hline Native law(s) & 64 \\
\hline Native chiefs & 43 \\
\hline Native authority & 29 \\
\hline
\end{tabular}

Table 3

The terms used in Table 3 clearly spell out an other i.e. one who is different and that deserves to be delineated. Native administration, native laws, native chiefs and so forth show apparently the 'native' as deserving a specialized help to suit his needs unlike his colonial counterpart whose case is the default or the normal. In essence, it shows that the 'natives' are in need of a kind of governance and laws which do not necessarily conform to general standards applied to the others especially colonial settlers or administrators. "These practices of exclusion, marking, and naming not only produced the African colonial identity but also functioned to reproduce a particular identity for the white settlers" (Doty 1996, 60).

Such collocationary pairs may have cognitive ideological impacts. The fixed usage of the collocational elements above leads us to the act of cognitive priming and to the possible establishment of a meaning association into a belief system. Hoey $(2007,7-8)$ argues that

each time we encounter a word (or syllable or combination of words), we subconsciously keep a record of the context and co-text of the word, so that cumulatively as we reencounter the word (or syllable or combination of words) we build up a record of its collocations. We are, I argue, primed by each encounter so that when we come to use the word (or syllable or combination of words) we characteristically replicate the contexts in which we had previously encountered it. Once this is recognized to account for collocation, we can see that the same processes will account for a number of other phenomena in the language.

Cognitive priming helps in the formation of language into beliefs and knowledge. The recurrent linguistic association of savagery with the African, for example, may lead to the belief in the veracity of the notion. This applies in all areas where there is a lexical naming and modification in the overall paper.

\section{CONCLUSION}

In conclusion, what has been done in this paper is to argue that the success achieved by the colonialists in making the subaltern a colonial subject is partly discursive. This is achieved in 
the way the mission and perception of colonial interests are objectified and mystified at the same time. Objectification occurs in the representation of the subaltern in terms that place them as convenient to colonial discourse of domination. And for this domination to work there has to be mystification as well. Mystification occurs when the limitations of perceptions are made covert. In the analysis, the black is clearly objectified, but the tools of this objectification are shown to be faultless through the manipulation of language. Language and discursive practices in the analysis as such play an integral part in the ideological formation of imperial interests. This helps in reinforcing colonial power relations and stabilizing them. Said $(1994,9)$ argues that neither imperialism nor colonialism is a simple act of accumulation and acquisition. These issues, he further maintains, are sustained by impressive ideological creations that include notions that certain territories and people require and beseech domination as well as forms of knowledge affiliated with domination: the vocabulary of classic nineteenth-century imperial culture is plentiful with words and concepts like "inferiors", or "subject races", "subordinate peoples", "dependency", "expansion" and "authority". The notion of an imperium has been ingrained by discourse for if not so how can, Said $(1994,11)$ asks in reference to India as a British colony, "a mere 4000 British civil servants assisted by 60000 soldiers and 90000 civilians (businessmen and clergy for the most part) billet themselves upon a country of 300 million people?"

\section{References}

Achebe, C. (1977). An Image of Africa: Racism in Conrad's “Heart of Darkness." Massachusetts Review, 18,

Anand, D. (2007). Western colonial representations of the other: The case of Exotica Tibet. New Political Science, 29(1), 23-42. doi:10.1080/07393140601170685

Ashcroft, B., Griffiths, G., \& Tiffin, H. (2000). Post-colonial studies: The key concepts. New York: Routledge.

Césaire, A. (1972). Discours on colonialism (discourse sur le colonialisme, engl.). New York: Monthly Review Press,U.S.

David, D. (2010, June 9). There is no African history. Retrieved March 3, 2017, from The Toynbee convector, https://davidderrick.wordpress.com/2010/06/09/there-is-no-african-history/

Davis, J. (1992). Tense in ethnography: some practical considerations. In J. Okely \& H. Callaway (Eds.), Anthropology and autobiography. New York: Taylor \& Francis.

Derrida, J. (1987). Positions. London: Continuum International Publishing Group.

Doty, R. L. (1996). Imperial encounters: The politics of representation in north south relations (3rd ed.). Minneapolis: University of Minnesota Press.

Downing, A., \& Locke, P. (2002). A university course in English grammar (2nd ed.). London: Routledge.

Fabian, J. (1983). Time and the other: How anthropology makes its object. New York: Columbia University Press.

Fairclough, N. (2001). Language and power (2nd ed.). New York: Longman.

Fairclough, N. (2003). Analysing discourse: Textual analysis for social research. New York: Taylor \& Francis.

Foucault, M. (1991). Discipline and Punish: the birth of a prison. London: Penguin.

Fowler, R., Hodge, B., Kress, G., \& Trew, T. (1979). Language and Control. Routeledge \& K.Paul.

Fredrickson, G. M. (1987). The black image in the white mind: The debate on Afro-American character and destiny, 1817-1914 (4th ed.). Middletown, CT: Distributed by Harper \& Row.

Green, D. (1984). Classified subjects: Photography and anthropology. Ten.8: photographic journal. Retrieved from http://lists.lib.mmu.ac.uk/items/8AFBAD8D-A2FD-39F8-ABAB-BA3202CCA842.html

Hall, S. (1997). The Spectacle of the Other. In S. Hall (Ed.), Representation: Cultural representations and signifying practices. Thousand Oaks, CA: Sage in association with the Open University.

Hart, C. (2014). Discourse, grammar and ideology: Functional and cognitive perspectives. New York, NY, United States: Continuum Publishing. 
Bello, U. (2017). Colonial Essentialism in Lord Lugard's "The Dual Mandate”, a Critical Textual Analysis. Advances in Social Sciences Research Journal, 4(6) $73-90$

Hodge, B., \& Kress, G. R. (1993). Language as ideology (2nd ed.). New York: Routledge.

Hoey, M. (2000). Textual interaction: An introduction to written discourse analysis. New York: Taylor \& Francis.

Hulme, P. (1986). COLONIAL ENCOUNTERS Europe and the native Caribbean, 1492-1797. London \& Newyork: Methuen.

Larymore, C. B. (2013). A Resident's Wife in Nigeria. Forgotten Books.

Lidchi, H. (1997). The Poetics and the Politics of Exhibiting other Cultures. In S. Hill (Ed.), Representation: Cultural representations and signifying practices. Thousand Oaks, CA: Sage in association with the Open University.

Lugard, L. F. (1965). The dual mandate in British tropical Africa (5th ed.). United Kingdom: Frank Cass Publishers.

Machin, D., \& Mayr, A. (2012). How to do critical discourse analysis: a multimodal introduction. Los Angeles: SAGE.

Memmi, A. (1990). The colonizer and the colonized (3rd ed.). London: Earthscan.

Rodney, W. (1973). How Europe underdeveloped Africa. London: Bogle-L'Ouverture Publications.

Said, E. W. (1994). Culture and imperialism. New York: Knopf Doubleday Publishing Group.

Simpson, P. (1993). Language, ideology, and point of view. London: Routledge.

Spivak, G. C. (1985). The Rani of Sirmur: An essay in reading the archives. History and Theory, 24(3), 247. doi: $10.2307 / 2505169$

Spivak, G. C. (2010). Can the subaltern speak? Reflections on the history of an idea. New York: Columbia University Press.

Taiwo, 0. (2010). How colonialism preempted modernity in Africa. Bloomington: Indiana University Press.

Umar, M. S. (2006). Islam and Colonialism: Intellectual Responses of Muslims of Northern Nigeria to British Colonial Rule. Leiden \& Boston: Brill.

van Dijk, T. A. (1996). Discourse Power and Access. In C. R. Caldas-Coulthard \& M. Coulthard (Eds.), Texts and practices: Readings in critical discourse analysis. London: Routledge.

van Dijk, T. A. A. (1998). Ideology: A multidisciplinary approach. Thousand Oaks, CA: Sage Publications.

Wallis, G. W. (1970). Chronopolitics: The impact of time perspectives on the dynamics of change. Social Forces, 49(1), 102. doi:10.2307/2575743 